\title{
Synthetic polyacrylamide as a potential flocculent to remove commercial chromium(III) oxide from aqueous suspension
}

\author{
M. Wiśniewska ${ }^{1} \cdot$ S. Chibowski ${ }^{1} \cdot$ T. Urban ${ }^{1}$
}

Received: 5 August 2015/Revised: 29 September 2015/Accepted: 30 November 2015/Published online: 14 December 2015

(C) Islamic Azad University (IAU) 2015

\begin{abstract}
The effects of solution $\mathrm{pH}$ and cationic group contents in polyacrylamide (PAM) macromolecules on the polymer adsorption mechanism on chromium(III) oxide surface were studied. The structure of PAM adsorption layer was also characterized to explain the changes in solid suspension stability. The following methods were applied: turbidimetry, spectrophotometry, potentiometric titration and microelectrophoresis. Thanks to them, the stability of the $\mathrm{Cr}_{2} \mathrm{O}_{3}$-polymer systems, polymer-adsorbed amount, surface charge density and zeta potential of solid particles were determined. The experimental results indicate that adsorption of cationic PAM increases with the rising $\mathrm{pH}$. The larger the content of cationic groups in PAM chains is, the higher the adsorption level is observed. The most effective chromium(III) oxide removal is achieved at $\mathrm{pH} 9$ after addition of PAM with the largest content of cationic groups (i.e. $80 \%$ ). The neutralization of solid surface negative charge by positively charged polymer chains (assuming more coiled conformation) is responsible for this.
\end{abstract}

Keywords Cationic group content $\cdot$ Cationic polyacrylamide $\cdot \mathrm{Cr}_{2} \mathrm{O}_{3}$ removal $\cdot$ Polymer adsorption . Suspension destabilization

M. Wiśniewska

wisniewska@hektor.umcs.lublin.pl

1 Department of Radiochemistry and Colloid Chemistry, Faculty of Chemistry, Maria Curie Sklodowska University, M. Curie Sklodowska Sq. 3, 20-031 Lublin, Poland

\section{Introduction}

Polymers belonging to the polyacrylamides group are often used because of their lower sensitivity to temperature and being prone to self-association. Moreover, they can be easily modified using the copolymerization reaction, which provides a wide range of their applications. In many cases, the polyacrylamide (PAM) macromolecules stabilize the colloidal dispersion by the steric effect or form polymeric bridges between the colloidal particles, leading to their destabilization. This polymer is very often used because of its high efficiency, low cost and not large requirements for its quality (Zhang and Miller 1996; Taylor and Nasr-El-Din 1998; Pefferkorn 1999; Nasser and James 2006; Tripathy and De 2006; Sojka et al. 2007).

Recently, various types of water contamination are serious problem from an ecological point of view. This is due to high industrial development. An important issue is the treatment of wastewater, industrial waste (Gupta et al. 2012a; Saleh and Gupta 2012a, b, c, d; Gupta and Saleh 2013; Gupta et al. 2013) and those from minerals processing. Removal of these pollutants requires application of appropriate methods such as adsorption, flocculation, filtration and evaporation (Gupta et al. 2011a; Saleh 2011; Saleh et al. 2011; Gościańska et al. 2012; Kaźmierczak et al. 2013; Nosal-Wiercińska 2012, 2013, 2014; Nowicki et al. 2013, 2015; Saleh 2015a, b). Nevertheless, the flocculation process is one of the most important and most frequently applied methods (Jin et al. 2003; Haydar and Aziz 2009; Wiśniewska et al. 2013).

Polyacrylamide is also used for treatment of drinking water, by simultaneous improvement of its physicochemical properties. Polyacrylamide finds application in production of paper, flotation of minerals and enhanced oil recovery and is used as a fertilizer inhibiting soil erosion. 
PAM is also used as a dispersant, spatial stabilizer and thickener (Sojka and Entry 2000; Entry et al. 2002; Zolfaghari et al. 2006; Xia 2007; Yuan et al. 2011).

The main aim of the present paper is determination of the impact of cationic group content of ionic polyacrylamide (PAM) on the conformation of its macromolecules in adsorption layer formed at $\mathrm{Cr}_{2} \mathrm{O}_{3}$ /polymer aqueous solution interface. The effect of solution $\mathrm{pH}$ was also examined. Explanation of PAM adsorption mechanism enabled clarification and understanding of $\mathrm{Cr}_{2} \mathrm{O}_{3}$ suspension stability in the polymer presence. The research presented in this paper is continuation of experiments concerning removal of undesirable solids from aqueous solutions. The previous paper focused on separation possibilities of $\mathrm{Cr}_{2} \mathrm{O}_{3}$ from the aqueous suspension by the use of anionic polyacrylamide (with a different content of cationic groups) (Wiśniewska et al. 2015a, b).

The world literature reports provide information about chromium(III) oxide removal using both synthetic and natural polymer flocculants such as polyacrylic acid, polyamino acids (anionic polyaspartic acid, cationic polylysine), its copolymers with polyethylene glycol, albumins (bovine serum albumin, ovalbumin, human serum albumin) and bacterial polysaccharide Sinorhizobium meliloti (Wiśniewska and Szewczuk-Karpisz 2013; Ostolska and Wiśniewska 2014a, b, 2015; Szewczuk-Karpisz and Wiśniewska 2014; Szewczuk-Karpisz et al. 2014). On the other hand, separation of $\mathrm{Cr}_{2} \mathrm{O}_{3}$ can be accomplished by application of various adsorbents, among other active carbons, mixed adsorbents of activated carbons and metal oxides as well as biosorbents (Gupta and Ali 2004; Gupta et al. 2007, 2011b, c, 2012b, c; Gupta and Rastogi 2009).

Chromium(III) oxide is one of the most frequently used dyes in the industry. It is applied for colouring glass, concrete, ceramic, plastic or leather. It is also used as a catalyst for organic syntheses. $\mathrm{Cr}_{2} \mathrm{O}_{3}$ is a very popular colourant in the production of banknotes and green ink. It is also used as an ingredient in cosmetics (eyeshadow) and dye in bronzers, lipsticks and cheek rose (Anger et al. 2005).

This compound is so widely applied due to the fact that it is not toxic and is the most stable (resistant to changes in temperature and weather conditions) compared to other green colourants. The pigment maintains the same colour. It may change tint in the cooler with blue tones at a temperature above $1000{ }^{\circ} \mathrm{C}$, which is caused by the increase in the solid particle diameter.

Due to the wide application of chromium oxide (III) in industry, its increased amount can be found in wastewaters. $\mathrm{Cr}_{2} \mathrm{O}_{3}$ has an intense green colour, and even its low concentrations can inhibit light penetration to greater depths of water. This can lead to oxygen deficiency caused by disruptions in the process of photosynthesis carried out by aquatic plants and algae (Bielicka et al. 2005; Oliveira 2012; Sarker et al. 2013). Therefore, it is important to look for new ways to remove coloured substances from wastewaters. One of them can be adsorption of macromolecules (i.e. ionic polyacrylamide) on the solid particle surfaces, making their removal much simpler.

\section{Materials and methods}

\section{Adsorbent characteristics}

Chromium(III) oxide (POCh) was used as adsorbent in the experiments. The BET-specific surface area of $\mathrm{Cr}_{2} \mathrm{O}_{3}$ was equal to $7.12 \mathrm{~m}^{2} / \mathrm{g}$ (BET method; Micrometritics ASAP 2405 analyzer). The mean grain size of the solid particles in water was $265 \mathrm{~nm}$. The average pore diameter of the solid particle was $6.1 \mathrm{~nm}$. These two parameters were obtained using photon correlation spectroscopy (Zetasizer 3000, Malvern Instruments).

\section{Polymeric samples characteristics}

Four samples of cationic polyacrylamide-PAM (Korona)-characterized by different contents of cationic groups were applied (Fig. 1; Table 1). The chemical formula of this polymer is:

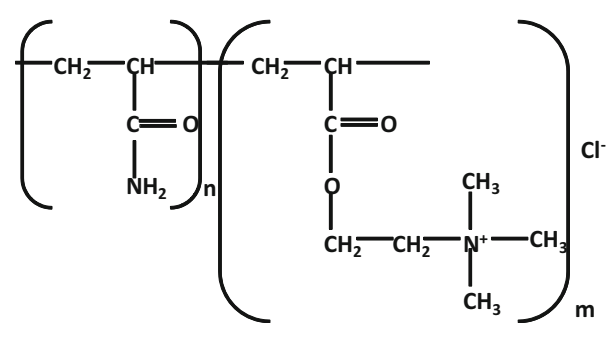

This PAM cationic form is obtained by copolymerization reaction of acrylamide with cationic monomer (i.e. containing the quaternary amine group). The $\mathrm{pK}_{\mathrm{b}}$ values of PAM solutions were determined by the potentiometric titration technique (Wiśniewska et al. 2015a), and the ionization degrees of cationic groups $(\alpha)$ were calculated (Table 1).

\section{Adsorption measurements}

All experiments were carried out at $25{ }^{\circ} \mathrm{C}$ in the solution of sodium chloride with the concentration $\left(1 \times 10^{-2} \mathrm{~mol} /\right.$ $\mathrm{dm}^{3}$ ), which played role of supporting electrolyte.

The static method was applied in adsorption measurements. The polymer concentrations were in the range 5-120 ppm. Three $\mathrm{pH}$ values were examined: 3,6 and 9 
Table 1 Characteristics of cationic polyacrylamide samples

\begin{tabular}{lllllll}
\hline Symbol & Molecular weight (Da) & Cationic group content $(\%)$ & $\mathrm{pK}_{\mathrm{b}}$ & \multicolumn{2}{c}{$\alpha(\%)$} & \\
\cline { 5 - 7 } & & & & $\mathrm{pH} \mathrm{3}$ & $\mathrm{pH} \mathrm{6}$ & $\mathrm{pH} \mathrm{9}$ \\
\hline PAM 8.5_20\% & $8,500,000$ & 20 & 10.1 & 99.9 & 99.9 & 92.6 \\
PAM 7.0_35\% & $7,000,000$ & 35 & 10.1 & 99.9 & 99.9 & 92.6 \\
PAM 7.0_50 \% & $7,000,000$ & 50 & 9.9 & 99.9 & 99.9 & 88.8 \\
PAM 7.0_80 \% & $7,000,000$ & 80 & 9.9 & 99.9 & 99.9 & 88.8 \\
\hline
\end{tabular}

$( \pm 0.1)$. The used solid mass was $0.07 \mathrm{~g}$. Next, suspensions were shaken in a water bath for $24 \mathrm{~h}$. Then, for each of them, the solid was centrifuged and $5 \mathrm{~cm}^{3}$ of supernatant was taken for analysis. The reaction of cationic polyacrylamide with a saturated solution of bromine, sodium formate and starch (in acetate buffer) (Scoggins and Miller 1975) was applied. The formed complex gives blue colour of the solution of different intensity (depending on the polymer concentration). The solution absorbance was measured after $5 \mathrm{~min}$ using the UV-Vis spectrophotometer (Carry 1000; Varian) at $585 \mathrm{~nm}$. The amount of the adsorbed polymer was determined from the difference between the PAM concentration in the solution before and after the adsorption process (using the calibration curve prepared earlier).

\section{Surface charge density determination}

The potentiometric titrations of $\mathrm{Cr}_{2} \mathrm{O}_{3}$ suspension without and with PAM (polymer concentrations 1 and $10 \mathrm{ppm}$ ) were performed in the thermostated Teflon vessel. The computer program Titr_v3 (author Janusz 1999) was used to the solid surface charge density calculation and $\mathrm{pH}_{\mathrm{pzc}}$ determination. $1.5 \mathrm{~g}$ of chromium(III) oxide was added into the vessel up to $50 \mathrm{~cm}^{3}$ of $\mathrm{PAM}-\mathrm{NaCl}$ solution (or only to $\mathrm{NaCl}$ solution). The suspension was titrated by $\mathrm{NaOH}$ of the concentration starting with the $\mathrm{pH}$ value about 3.5. The measuring set was composed of the following parts: burette Dosimat 665 (Methrom), thermostat RE204 (Lauda), pH meter PHM 240 (Radiometer), computer and printer.

\section{Zeta potential measurements}

$\mathrm{Cr}_{2} \mathrm{O}_{3}$ suspensions (without and with PAM) were prepared, adding $0.02 \mathrm{~g}$ of $\mathrm{Cr}_{2} \mathrm{O}_{3}$ to $100 \mathrm{~cm}^{3}$ of $\mathrm{NaCl}$ solution or $\mathrm{PAM}-\mathrm{NaCl}$ solution (polymer concentrations 1 and $10 \mathrm{ppm}$ ) solutions. After the sonification process, the obtained suspension was divided into 6 parts of the same volume. Then in each of them, the $\mathrm{pH}$ value was adjusted to: $3,4.5,5.5,6.5,8.5$ and $10 \pm 0.1$, respectively. The zeta potential was measured with the Zetasizer Nano ZS using the universal dip cell and MPT-2 titrator (Malvern Instruments).

\section{Determination of $\mathrm{Cr}_{2} \mathrm{O}_{3}$ suspension stability without and with polymer}

Stability measurements of the $\mathrm{Cr}_{2} \mathrm{O}_{3}-\mathrm{NaCl}$ and $\mathrm{Cr}_{2} \mathrm{O}_{3}-$ PAM-NaCl systems were made using Turbiscan Lab ${ }^{\text {Expert }}$ with the cooling module TLAb Cooler. The suspension of $0.2 \mathrm{~g}$ of oxide in $20 \mathrm{~cm}^{3}$ of $\mathrm{NaCl}$ solution (or PAM- $\mathrm{NaCl}$, $\mathrm{C}_{\mathrm{PAM}} 100 \mathrm{ppm}$ ) was prepared. Each experiment of suspension stability lasted $15 \mathrm{~h}$, and every $15 \mathrm{~min}$ the respective data were collected.

As a result, the curves of transmission (and backscattering) intensities of light directed towards the examined suspension as a function of time were obtained. These data enable special parameters calculation (TLab EXPERT 1.13 and Turbiscan Easy Soft programs) which characterize suspension stability. There are: the stability coefficient Turbiscan Stability Index (TSI), the formed sediment thickness, the aggregate (flock) size and the aggregate (flock) migration velocity.

The following dependencies were applied for this purpose:

$\mathrm{TSI}=\sqrt{\frac{\sum_{i=1}^{n}\left(x_{i}-x_{\mathrm{BS}}\right)^{2}}{n-1}}$

where $x_{i}$ is average backscattering for each minute of measurement, $x_{\mathrm{BS}}$ average $x_{1}$, and $n$ number of single measurement during the total time of the experiment,

$V(\phi, d)=\frac{\left|\rho_{\mathrm{p}}-\rho_{\mathrm{c}}\right| g d^{2}}{18 v \rho_{\mathrm{c}}} \cdot \frac{[1-\phi]}{\left[1+\frac{4.6 \phi}{(1-\phi)^{3}}\right]}$

where $v$ is aggregate migration velocity, $\rho_{\mathrm{c}}$ continuousphase density, $\rho_{\mathrm{p}}$ particle density, $d$ particle mean diameter, $v$ continuous-phase dynamic viscosity, and $\phi$ volume fraction of dispersed solid. 


\section{Results and discussion}

\section{Adsorption mechanism of polyacrylamide on the chromium(III) oxide surface}

The exemplary adsorption isotherms of polyacrylamide on the chromium(III) oxide surface, obtained for the polymer samples containing $80 \%$ of cationic groups, are presented in Fig. 1.

The analysis of these dependencies shows that in all examined systems, adsorption of cationic polyacrylamide on the solid surface increases with the increasing $\mathrm{pH}$. This is due to the changes in polymer-surface electrostatic interactions (degree of PAM macromolecules ionization, sign and surface charge density of the metal oxide). The macromolecules of cationic PAM contain two types of functional groups. There are: nonionic amide groups that do not dissociate in aqueous solution and specified amounts $(20,35,50$ and $80 \%)$ of cationic groups (quaternary amine moiety). The latter dissociate over a range of the studied $\mathrm{pH}$ (i.e. 3-10), whereby they are a source of positive charge of PAM macromolecules. Total dissociation of all cationic groups takes place at the $\mathrm{pH}$ values of 3 and 6 (approximately $99.9 \%$, Table 1 ). With the $\mathrm{pH}$ rise, the ionization degree of cationic groups decreases slowly and at $\mathrm{pH} 9$ it reaches the value in the range $88.8-92.6 \%$. At $\mathrm{pH}$ equal to the $\mathrm{pK}_{\mathrm{b}}$ value ranging 9.9-10.1 for the applied polymer samples, the dissociation degree of the polymer cationic groups is 0.5 (Table 1 ).

It is obvious that the adsorption affinity of positively charged macromolecules depends on the sign and density of the surface charge of chromium(III) oxide. The used adsorbent is characterized by the $\mathrm{pH}_{\mathrm{pzc}}$ (pzc-point of zero charge) of 5.9-6.0. At this $\mathrm{pH}$ value, the total surface charge of the solid is zero, which means that the concentration of positively charged surface groups is equal to that of negative groups. Thus, in the $\mathrm{pH}$ range lower than

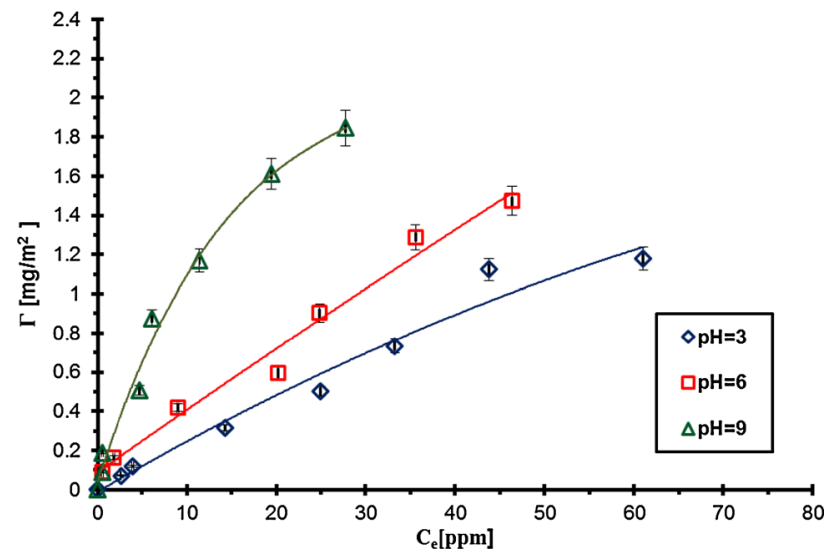

Fig. 1 Adsorption isotherms of PAM 7.0_80 \% on the $\mathrm{Cr}_{2} \mathrm{O}_{3}$ surface for different solution $\mathrm{pH}$
5.9, the $\mathrm{Cr}_{2} \mathrm{O}_{3}$ surface charge is positive, which is the reason for the electrostatic repulsion between the charged polymer chains and adsorbent. It is worth noting that the total charge of adsorbent is dependent on concentrations of the following surface groups: neutral $(=\mathrm{CrOH})$ and charged $\left(=\mathrm{CrO}^{-},=\mathrm{CrOH}_{2}^{+}\right)$. On the other hand, in the range of $\mathrm{pH}$ values above $\mathrm{pH}_{\mathrm{pzc}}$ of metal oxide, there are attractive electrostatic interactions between the PAMpositive functional groups and negatively charged solid surface. However, the occurrence of the cationic polymer adsorption at $\mathrm{pH}<5.9$ (the surface is positively charged, and electrostatic repulsion between the adsorbing macromolecules and that surface takes place) testifies to the binding of the polymer with the surface active sites through hydrogen bridges.

The total dissociation of the PAM cationic groups at $\mathrm{pH}$ 3 causes considerable development of polymeric chains. This is evidenced by the previously determined values of the hydrodynamic radius $\left(R_{\mathrm{h}}\right)$ of macromolecules in the bulk solution (Wiśniewska et al. 2015a). The analysis of the obtained values of this parameter (Table 2) indicates

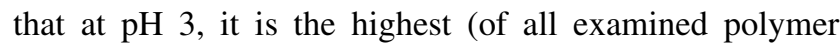
samples). Thus, the electrostatic repulsion between the polymer segments (containing positively charged functional groups) belonging to the same or different macromolecules leads to the adoption of more developed conformation in the solution.

Adsorption of these developed chains on the positively charged solid surface takes place under unfavourable electrostatic conditions. Mutual adsorbate-adsorbent repulsion results in the lowest adsorption of polyacrylamide at $\mathrm{pH} 3$. The structure of the polymer adsorption layer is characterized mainly by the loop and tail structures extended into the bulk solution. Only a few polymer segments are directly bound to the adsorbent surface groups forming train structures. Probably hydrogen bonds

Table 2 Hydrodynamic radius $\left(R_{\mathrm{h}}\right)$ of polymer macromolecules in the solution

\begin{tabular}{lll}
\hline Polymer & $\mathrm{pH}$ & $R_{\mathrm{h}}(\mathrm{nm})$ \\
\hline PAM 8.5_20\% & 3 & 71.9 \\
& 6 & 56.1 \\
& 9 & 40.1 \\
PAM 7.0_35 \% & 3 & 74.8 \\
& 6 & 58.1 \\
& 9 & 45.3 \\
PAM 7.0_50 \% & 3 & 86.7 \\
& 6 & 79.5 \\
& 9 & 74.3 \\
PAM 7.0_80 \% & 3 & 87.5 \\
& 6 & 81.4 \\
& 9 & 76.5 \\
\hline
\end{tabular}




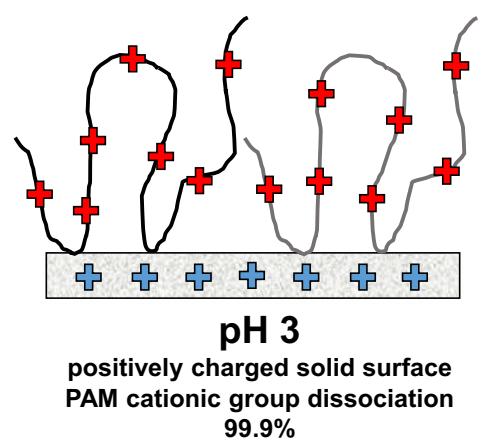

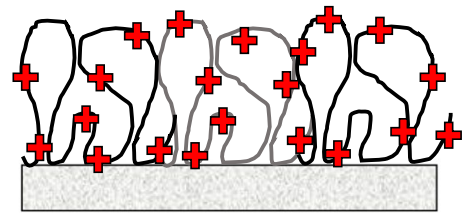

pH 6

neutral solid surface PAM cationic group dissociation $99.9 \%$

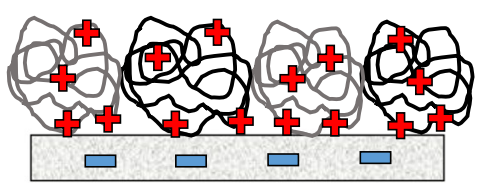

pH 9

negatively charged solid surface PAM cationic group dissociation $88.9 \%$

Fig. 2 Schematic presentation of cationic PAM adsorption mechanism on the $\mathrm{Cr}_{2} \mathrm{O}_{3}$ surface for different solution $\mathrm{pH}$

between the hydroxyl groups of chromium(III) oxide and the functional groups of the polymer are responsible for PAM adsorption. Both amide and cationic groups of PAM as well as all types of $\mathrm{Cr}_{2} \mathrm{O}_{3}$ surface groups (i.e. neutral and charged $\left.=\mathrm{CrOH},=\mathrm{CrO}^{-},=\mathrm{CrOH}_{2}{ }^{+}\right)$can be involved in formation of hydrogen bonds (Kasprzyk-Hordern 2004).

At $\mathrm{pH}$ 6, PAM adsorption on the solid surface increases significantly. Under these conditions, the resultant surface charge is practically zero $\left(\mathrm{pH}_{\mathrm{pzc}}=5.9\right)$. On the other hand, adsorbing macromolecules exhibit significant expansion due to the almost complete ionization. In the absence of electrostatic adsorbate-adsorbent interaction, more polymer segments are directly bonded with the surface (through train structures), which manifests in less developed conformation towards bulk solution. Such a conformation of the adsorbed macromolecule provides higher packing density of the adsorption layer (comparing to that at $\mathrm{pH} 3$ ), which leads to polymer adsorption increase.

The most favourable electrostatic conditions for the adsorption of cationic polyacrylamide on the surface of chromium(III) oxide are found at $\mathrm{pH} 9$. The surface charge of $\mathrm{Cr}_{2} \mathrm{O}_{3}$ assumes a negative value, and positively charged macromolecules have a more coiled conformation (dissociation degree of cationic groups in their chain reaches 88.8-92.6\%). As a result, more of the polymer molecules can locate on the unit of the solid surface, which results in the highest packing of adsorption layer (the largest adsorbed amount of PAM).

The mechanism of cationic PAM adsorption on the $\mathrm{Cr}_{2} \mathrm{O}_{3}$ surface for different solution $\mathrm{pH}$ is schematically illustrated in Fig. 2.

The polyacrylamide adsorption at the chromium(III) oxide-solution interface also affects significantly the content of the cationic groups in the polymer chains. For a given $\mathrm{pH}$ of the solution, it is observed that the more numerous the cationic groups in the polymer chain are, the larger the amount of adsorbed PAM is. The comparison of the adsorption amount of polyacrylamide samples

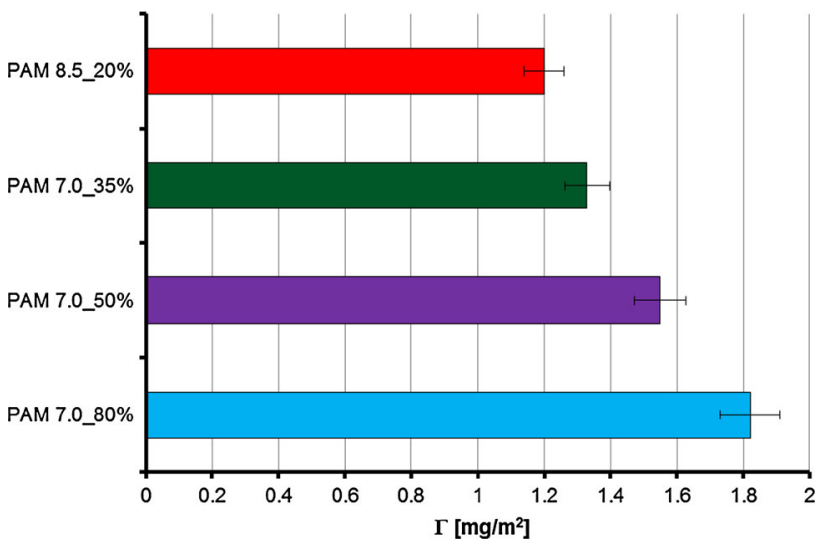

Fig. 3 Adsorbed amounts of PAM on the $\mathrm{Cr}_{2} \mathrm{O}_{3}$ surface for different cationic group contents in the polymer chains, $\mathrm{C}_{\mathrm{PAM}}=100 \mathrm{ppm}$

characterized by different contents of cationic groups in their chains at $\mathrm{pH} 9$ is presented in Fig. 3. A larger number of these groups are equivalent to the more positively charged macromolecules, which leads to a higher adsorption on the negative metal oxide surface at $\mathrm{pH} 9$.

In addition, the presence of a similar trend for two other tested $\mathrm{pH}$ values (i.e. 3 and 6), at which there is no adsorbent-adsorbate attraction, shows preferential binding of cationic PAM groups with the solid surface, in relation to the nonionic amide groups of the polymer.

\section{Influence of cationic polyacrylamide adsorption on the electrokinetic properties of chromium(III) oxide-aqueous polymer solution system}

Figure 4 presents the curves showing the dependence of the surface charge density of $\mathrm{Cr}_{2} \mathrm{O}_{3}\left(\sigma_{0}\right)$ as a function of solution $\mathrm{pH}$ obtained for the systems with and without polymer. On the other hand, Fig. 5 represents the changes in the zeta potential $(\zeta)$ of $\mathrm{Cr}_{2} \mathrm{O}_{3}$ particles in the absence and presence of PAM. Their analysis shows that the 


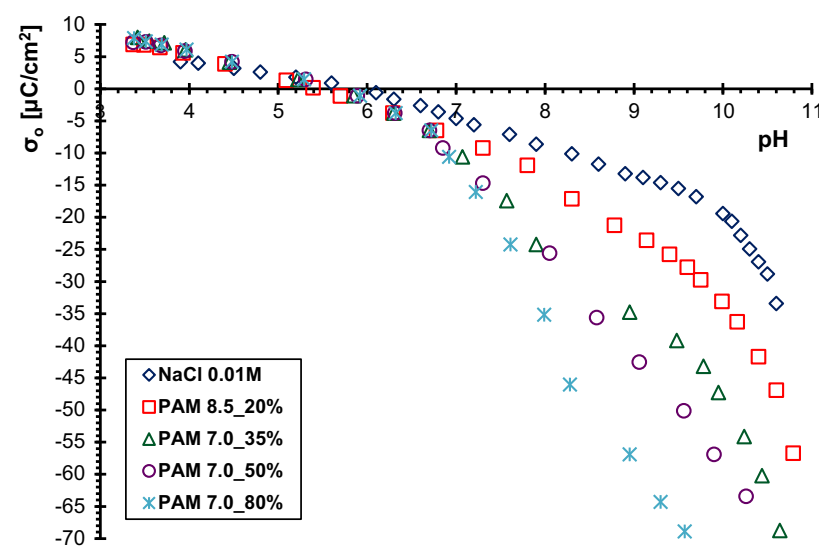

Fig. 4 Surface charge density of $\mathrm{Cr}_{2} \mathrm{O}_{3}$ in the absence and presence of cationic PAM, $\mathrm{C}_{\mathrm{PAM}}=10 \mathrm{ppm}$

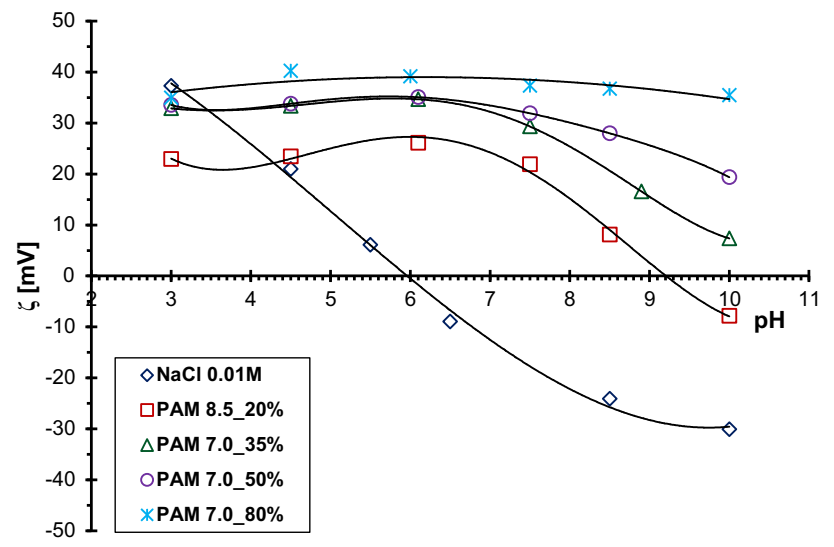

Fig. 5 Zeta potential of $\mathrm{Cr}_{2} \mathrm{O}_{3}$ particles without and with cationic $\mathrm{PAM}, \mathrm{C}_{\mathrm{PAM}}=10 \mathrm{ppm}$

adsorption of cationic polyacrylamide results in a noticeable reduction in the surface charge density of the solid compared to the system without PAM in the $\mathrm{pH}$ range lower than $\mathrm{pH}_{\mathrm{pzc}}$. The effect of this reduction is greater for a higher polymer concentration (Table 3 ). A different situation is observed in the case of zeta potential changes, where the presence of the PAM adsorption layer around the solid particles causes a significant increase in the value of the electrokinetic potential.

The changes in the structure of the electrical double layer at the solid-solution interface due to the polymer adsorption are reflected in the location of $\mathrm{pH}_{\mathrm{pzc}}$ and $\mathrm{pH}_{\mathrm{iep}}$ points, compared to those obtained for the systems without polyacrylamide (Table 3 ). $\mathrm{pH}_{\text {iep }}$ point (iep-isoelectric point) determines the $\mathrm{pH}$ at which the zeta potential characterizing the charge of slipping plane is zero. Adsorption of cationic polymer causes a shift of $\mathrm{pH}_{\mathrm{pzc}}$ of $\mathrm{Cr}_{2} \mathrm{O}_{3}$ towards lower values of $\mathrm{pH}$. In turn, the $\mathrm{pH}_{\text {iep }}$ point
Table $3 \mathrm{pH}_{\mathrm{pzc}}$ and $\mathrm{pH}_{\text {iep }}$ values for $\mathrm{Cr}_{2} \mathrm{O}_{3}$ systems without and with PAM

\begin{tabular}{|c|c|c|c|c|}
\hline \multirow[t]{2}{*}{ System } & \multicolumn{2}{|l|}{$\mathrm{pH}_{\mathrm{pzc}}$} & \multicolumn{2}{|l|}{$\mathrm{pH}_{\mathrm{iep}}$} \\
\hline & $1 \mathrm{ppm}$ & $10 \mathrm{ppm}$ & $1 \mathrm{ppm}$ & $10 \mathrm{ppm}$ \\
\hline $\mathrm{Cr}_{2} \mathrm{O}_{3}$ & 5.9 & 6.0 & & \\
\hline $\mathrm{Cr}_{2} \mathrm{O}_{3}$-PAM 8.5_20\% & 5.01 & 5.44 & 9.1 & 9.2 \\
\hline $\mathrm{Cr}_{2} \mathrm{O}_{3}$-PAM 7.0_35\% & 5.38 & 5.69 & 9.5 & $>10$ \\
\hline $\mathrm{Cr}_{2} \mathrm{O}_{3}$-PAM 7.0_50\% & 5.58 & 5.68 & 9.9 & $>10$ \\
\hline $\mathrm{Cr}_{2} \mathrm{O}_{3}$-PAM 7.0_80\% & 5.6 & 5.65 & 13.4 & $>10$ \\
\hline
\end{tabular}

of the systems containing polymer moves considerably in the direction of alkaline $\mathrm{pH}$.

The presence of cationic polyacrylamide results in minimal changes in the surface charge density in the range of $\mathrm{pH}<\mathrm{pH}_{\mathrm{pzc}}$. This is probably due to the lowest adsorption of the polymer under these conditions and expanded conformation of macromolecules at the solidsolution interface. Mutual electrostatic repulsion of positively charged fragments of the polymer chains in the adsorption layer and their repulsion from the positively charged surface of chromium(III) oxide enable binding only a few PAM segments to the adsorbent surface. This results in barely noticeable changes in the $\sigma_{0}$ value of the polymer presence.

In turn, in the range of $\mathrm{pH}>\mathrm{pH}_{\mathrm{pzc}}$, $\mathrm{PAM}$ adsorption causes marked reduction in the $\mathrm{Cr}_{2} \mathrm{O}_{3}$ surface charge density in relation to the polymer absence system. This is due to the interactions of the polycation macromolecules with the surface active sites, whose presence in the surface layer imposes formation of the additional negatively charged groups of the adsorbent. As a result, the total value of $\sigma_{0}$ is reduced. This effect is particularly pronounced in the case of higher polyacrylamide concentrations. In this case, the higher is the observed reduction in the surface charge density of metal oxide, the larger is the content of cationic groups in the polymer chain. Thus, a larger number of positive charges located along the adsorbing macromolecules induce an increasing number of negative surface groups.

The presence of PAM adsorption layers around chromium(III) oxide particles results in significant changes in the value of the diffusion layer potential, particularly evident in a large increase in the zeta potential (Fig. 5). In addition, the more significant the shift of $\mathrm{pH}_{\text {iep }}$ to higher $\mathrm{pH}$ values caused by the polymer presence is, the higher the percentage of cationic functional groups in the polymer chain is (Table 3 ). 
The observed increase in the electrokinetic potential of the solid in the cationic polymer presence is due to the placement of positive charges originating from the functional groups of adsorbed PAM macromolecules in the slipping plane. These groups are present in the loop and tail structures of polyacrylamide chains bounded with the surface. Therefore, it is obvious that the higher the content of these groups in the adsorbed macromolecules is, their greater number is located in the electrical double layer (edl) formed around the particles of chromium(III) oxide. Another effect which influences the value of the zeta potential in the polymer presence is the slipping plane shift from the surface of the colloidal particle. This phenomenon causes the decrease in the electrokinetic potential. However, the experimentally observed value of zeta potential is dependent on the contribution of the effects: the presence of polymer cationic groups in the diffusion part of edl and the slipping plane shift.

\section{Stability of chromium(III) oxide suspension in the cationic polyacrylamide presence}

The selected results of turbidimetry measurements obtained for the suspension in the absence of the polymer at $\mathrm{pH} 9$ and in the presence of PAM 7.0_80 \% at pH 3 are presented in Figs. 6 and 7, respectively. The first one is an example of highly unstable system, whereas the latter one is characterized by higher stability. Changes in the stability of $\mathrm{Cr}_{2} \mathrm{O}_{3}$ suspension without and with polyacrylamide can be examined based on the transmission and backscattering curves course.

The levels of the transmission and backscattering (expressed in \%) are indicated on the ordinate axis, whereas the height (expressed in $\mathrm{mm}$ ) corresponding to different levels of the test suspension in the measurement vial is marked on the abscissa axis. The length of this vial is $70 \mathrm{~mm}$, but the suspensions were poured into the level of approximately $45 \mathrm{~mm}$. Thus, the value of $0 \mathrm{~mm}$ means the bottom of the vial, whereas $45 \mathrm{~mm}$ is the upper level of the suspension. The total measurement time for the single system was $15 \mathrm{~h}$, during which every $15 \mathrm{~min}$ the individual curves (i.e. scans) were recorded. Different colours of transmission and backscattering curves correspond to these intervals of time, e.g. $t=0 \mathrm{~h}$ (pink), $t=7 \mathrm{~h}$ (green), $t=15 \mathrm{~h}$ (red).

The analysis of these curves indicates that the $\mathrm{NaCl}-$ $\mathrm{Cr}_{2} \mathrm{O}_{3}$ system at $\mathrm{pH} 9$ (Fig. 6) is much less stable than the $\mathrm{NaCl}-\mathrm{Cr}_{2} \mathrm{O}_{3}-\mathrm{PAM}$ 7.0_80 \% suspension at pH 3 (Fig. 7). In the case of the former unstable system, the transmission level reaches 60-75\% practically at the entire length of the measurement vial, with the exception for the range 0-11 mm, when the transmission falls to zero. In the same range $(0-11 \mathrm{~mm})$, the backscattering light reaches its maximum level of 50-55\% as a result of an appearing peak. Its width determines thickness of the formed sediment, which in this case is large being about $11 \mathrm{~mm}$. The

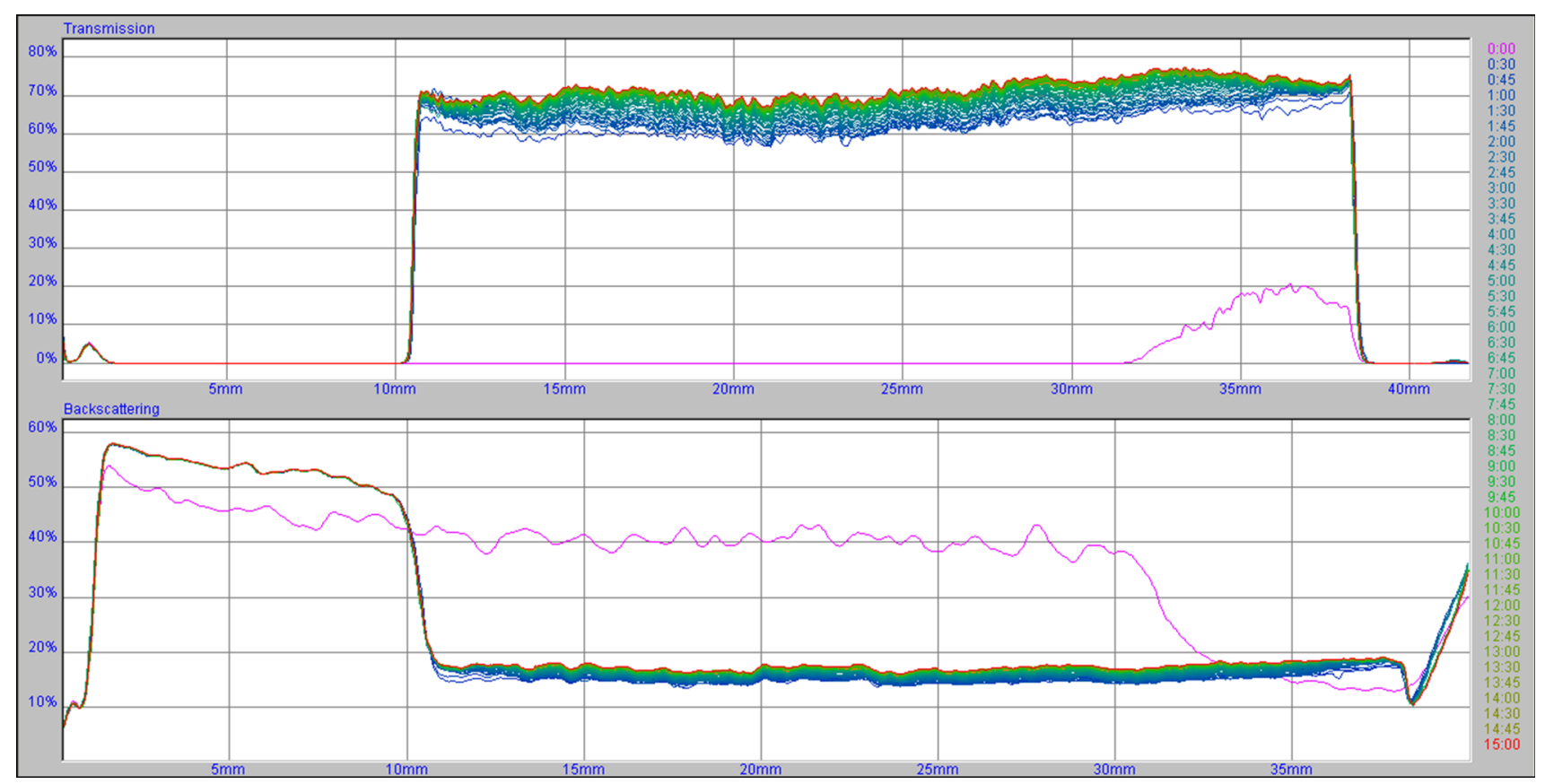

Fig. 6 Transmission and backscattering for $\mathrm{Cr}_{2} \mathrm{O}_{3}-\mathrm{NaCl}$ at $\mathrm{pH} 9$ 


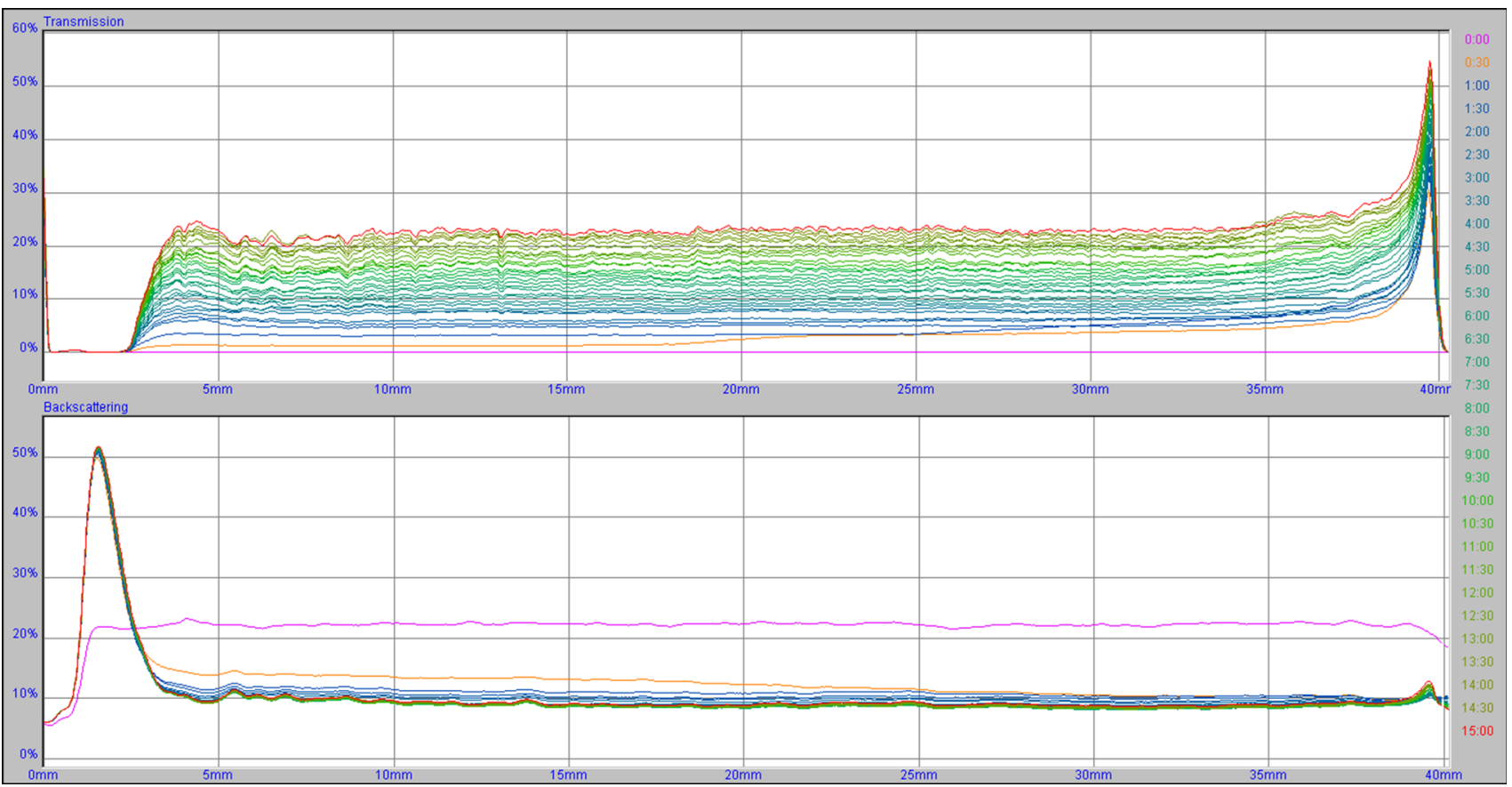

Fig. 7 Transmission and backscattering for $\mathrm{NaCl}-\mathrm{Cr}_{2} \mathrm{O}_{3}-\mathrm{PAM} 7.0 \_80 \%$ at pH 3

individual curves in Fig. 6 are located very close to each other or even overlap (with the exception for the first scan corresponding to $t=0$ ). This means that in the initial stage of the measurement, the suspension quickly reached a state of near the end, i.e. high instability.

For a more stable system (Fig. 7), the sediment thickness is about $2.5 \mathrm{~mm}$. In addition, the transmission is maintained at a much lower level about 20-25\%. The clarification process occurs only in a thin surface layer of the sample-the curves show a transmission peak of about $1 \mathrm{~mm}$ thickness. Moreover, migration of aggregates in the sample is more gradual (individual transmission curves do not overlap, but are clearly far apart).

A convenient parameter that allows estimation of the suspension stability is the stability coefficient TSI (TSITurbiscan Stability Index). Possible values of TSI are in the range $0-100$. For highly stable systems, TSI assumes a value close to zero, whereas increase in this parameter indicates decrease in the system stability. Moreover, for all examined systems, the following parameters characterizing their stability were determined: thickness of sediment layer, size of aggregates and velocity of their migration in the suspension. Their values are given in Tables 4 and 5 .

The chromium(III) oxide suspension without the polymer is relatively stable at $\mathrm{pH} 3(\mathrm{TSI}=12.8)$. On the other
Table 4 TSI stability coefficients and sediment thicknesses for $\mathrm{Cr}_{2} \mathrm{O}_{3}$ suspension in the absence and presence of PAM, $\mathrm{C}_{\mathrm{PAM}}=100 \mathrm{ppm}$

\begin{tabular}{|c|c|c|c|c|c|c|}
\hline \multirow[t]{2}{*}{ System } & \multicolumn{3}{|l|}{ TSI } & \multicolumn{3}{|c|}{ Sediment thickness $(\mathrm{mm})$} \\
\hline & $\mathrm{pH} 3$ & pH 6 & $\mathrm{pH} 9$ & $\mathrm{pH} 3$ & pH 6 & pH 9 \\
\hline $\mathrm{Cr}_{2} \mathrm{O}_{3}$ & 12.8 & 61.0 & 29.3 & 9.5 & 15.8 & 11.0 \\
\hline PAM 8.5_20\% & 31.8 & 27.0 & 34.1 & 2.5 & 2.1 & 2.8 \\
\hline PAM 7.0_50 \% & 28.1 & 21.2 & 33.9 & 2.3 & 2.0 & 2.6 \\
\hline PAM $7.0 \_80 \%$ & 34.5 & 38.1 & 44.4 & 2.5 & 2.4 & 3.1 \\
\hline
\end{tabular}

hand, at $\mathrm{pH} 6$ it undergoes considerable destabilization $(\mathrm{TSI}=61)$, and at $\mathrm{pH} 9$ it reaches an intermediate state $($ TSI $=29.3)$. These data are in accordance with other parameters characterizing the system stability, namely at pH 6 the greatest thickness of sediment and the fastest aggregates migration are observed.

The addition of polyacrylamide causes noticeable deterioration of $\mathrm{Cr}_{2} \mathrm{O}_{3}$ suspension stability at the $\mathrm{pH}$ values 3 and 9. This effect is the greatest for the polymer samples characterized by the largest content of cationic groups. This is manifested in the increase in aggregates size formed with solid particles and polymer chains (i.e. flocks). However, at pH 6 improvement of examined suspensions 
stability in the polymer presence is observed. Under these conditions, the polymer containing the smallest number of cationic groups improves $\mathrm{Cr}_{2} \mathrm{O}_{3}$ suspension stability most effectively. This is demonstrated in decrease in aggregate sizes, their slower migration and smaller thickness of formed sediment.

\section{Impact of cationic polyacrylamide on the mechanism of chromium(III) oxide suspension stability}

$\mathrm{Cr}_{2} \mathrm{O}_{3}$ suspensions not containing the polymer are characterized by the highest stability at $\mathrm{pH} 3$. This is a result of electrostatic stabilization mechanism. The zeta potential of solid particles achieved a high value of about $+40 \mathrm{mV}$ (Fig. 4). It turns out that it is sufficient to obtain an effective repulsion between particles surrounded by electrical double layers (composed of supporting electrolyte ions). Thus, the process of solid particle aggregation in the system is significantly inhibited.

The main reason for the drastic destabilization of the suspension at $\mathrm{pH} 6$ is the fact that at this $\mathrm{pH}$ value is the $\mathrm{pH}_{\text {iep }}$ point of $\mathrm{Cr}_{2} \mathrm{O}_{3}$ (zeta potential is equal to zero). Zero charge of diffusion layer means that there are no electrostatic repulsion forces between particles. This greatly facilitates their mutual collisions leading to system coagulation.

The system without polyacrylamide at $\mathrm{pH} 9$ is characterized by the intermediate stability obtained at the $\mathrm{pH}$ values 3 and 6 . Under these conditions, the absolute value of the $\zeta$ potential of chromium(III) oxide particles is about $25 \mathrm{mV}$ (Fig. 4), which is not sufficient to ensure such effective stabilization of the suspension as it is at $\mathrm{pH} 3$.

Reduction in the $\mathrm{Cr}_{2} \mathrm{O}_{3}$ suspension stability due to the polymer addition at $\mathrm{pH} 3$ is caused by bridging interactions appearance. This is facilitated by the lowest adsorption of cationic PAM and the most extended conformation of its macromolecules on the solid surface. The polymer chain stretched in the direction of bulk solution can be adsorbed on the surface of at least two colloidal particles, linking them together and forming flocks. Lower degree of polymer packing in the adsorption layer at $\mathrm{pH} 3$ makes that there are free places on the solid surface, which could adsorb a fragment of the macromolecule already connected with another solid particle. This results in the formation of single polymer bridges and the appearance of bridging flocculation.

At the highest percentage of cationic groups in the PAM macromolecules, the greatest effect of stability deterioration is achieved. Development of the polymer chain on the surface in this case is significant, leading to a more efficient process of bridging.

Significant improvement of the $\mathrm{Cr}_{2} \mathrm{O}_{3}$ suspension stability in the PAM presence at $\mathrm{pH} 6$ is due to higher adsorption of the polymer and creation of more hermetic adsorption layers on the metal oxide surface. The mechanism of this process is electrosteric. In addition to the steric interactions resulting in increase in the effectiveness of repulsion between the colloidal particles coated with a polymer, electrostatic repulsion between the polymer cationic groups located in the adsorption layers is also of significant importance. The least extended conformation of PAM (with the lowest content of carboxyl groups) makes that the adsorption layer is the most packed (as compared to the others formed by the polymers containing an increasing number of cationic groups). In this case, the steric effects are the most effective, providing the greatest stability of $\mathrm{Cr}_{2} \mathrm{O}_{3}-\mathrm{PAM} 7.0 \_20 \%$ at pH 6 .

In turn, at $\mathrm{pH} \mathrm{9,} \mathrm{the} \mathrm{presence} \mathrm{of} \mathrm{polyacrylamide} \mathrm{results}$ in slight deterioration of the solid suspension stability. The main reason for the observed destabilization may be neutralization of the negative charge of the metal oxide particles by adsorbed cationic polymer chains. They adopt less extended conformation on the solid surface because the degree of functional groups ionization decreases. Solid particles covered with more coiled macromolecules do not repel efficiently enough to prevent them from joining in larger units and flocks formation. PAM 7.0_80 \% at pH 9 shows the greatest destabilization properties for the chromium(III) oxide water suspension.
Table 5 Aggregate sizes and its migration velocity for $\mathrm{Cr}_{2} \mathrm{O}_{3}$ suspension in the absence and presence of PAM, $\mathrm{C}_{\mathrm{PAM}}=100 \mathrm{ppm}$

\begin{tabular}{llllllll}
\hline System & \multicolumn{3}{l}{ Aggregate size $(\mu \mathrm{m})$} & & & \multicolumn{3}{l}{ Aggregate sedimentation velocity $(\mu \mathrm{m} / \mathrm{min})$} \\
\cline { 2 - 3 } & $\mathrm{pH} \mathrm{3}$ & $\mathrm{pH} \mathrm{6}$ & $\mathrm{pH} \mathrm{9}$ & & $\mathrm{pH} \mathrm{3}$ & $\mathrm{pH} \mathrm{6}$ & $\mathrm{pH} \mathrm{9}$ \\
\hline $\mathrm{Cr}_{2} \mathrm{O}_{3}$ & 0.08 & 0.54 & 0.13 & & 0.83 & 4.1 & 2.23 \\
PAM 8.5_20 \% & 0.04 & 0.095 & 0.1 & & 0.19 & 1.14 & 1.15 \\
PAM 7.0_50 \% & 0.12 & 0.06 & 0.14 & & 0.16 & 0.25 & 1.24 \\
PAM 7.0_80 \% & 0.16 & 0.074 & 0.34 & & 0.34 & 0.28 & 1.26 \\
\hline
\end{tabular}


Our previous studies indicated that cationic polyacrylamide causes the most effective destabilization of chromium(III) oxide suspension at $\mathrm{pH}$ 9. Other examined polymers - both synthetic [poly(acrylic acid) PAA, anionic polyacrylamide PAM, poly(aspartic acid) ASP, block copolymer of poly(aspartic acid) with poly(ethylene glycol) ASP-b-PEG] and natural (bovine serum albumin BSA, ovalbumin OVA, human serum albumin HSA, bacterial polysaccharide EPS) - are not as effective destabilizers under this $\mathrm{pH}$ condition (Wiśniewska and Szewczuk-Karpisz 2013; Ostolska and Wiśniewska 2014a, b, 2015; Szewczuk-Karpisz and Wiśniewska 2014; Szewczuk-Karpisz et al. 2014).

\section{Conclusion}

The stability mechanism of the chromium(III) oxide suspension containing cationic polyacrylamide (PAM) was determined. The influence of the content of polymer functional groups (positively charged) was examined.

At $\mathrm{pH} 3$, the reduction in the $\mathrm{Cr}_{2} \mathrm{O}_{3}$ suspension stability in the PAM presence was obtained. It is caused by polymer bridges formation between the solid particles and adsorbed macromolecules assuming extended conformation. The lowest adsorption of cationic PAM facilitates bridging flocculation occurrence due to incomplete coverage of the solid surface by the adsorbate.

Higher adsorption of the polymer and the creation of more packed adsorption layers on the solid surface at $\mathrm{pH} 6$ are the main reason for significant improvement of the $\mathrm{Cr}_{2} \mathrm{O}_{3}$ suspension stability. The mechanism of this process is electrosteric-repulsion of solid particles was provided by the presence of both polymeric layer (steric forces) and charges of PAM chains (electrostatic forces).

Slight deterioration of the solid suspension stability at $\mathrm{pH} 9$ due to polyacrylamide addition is observed. This destabilization is a result of neutralization of the negative charge of the metal oxide particles by positively charged polymer chains (more coiled conformation).

The greater the content of cationic groups in the polymeric chains is, the greater the deterioration of suspension stability occurs ( $\mathrm{pH}$ values 3 and 9). Development of the polymer chain containing more numerous cationic groups is greater, leading to more efficient destabilization processes in the suspension.

The greatest destabilization properties in relation to chromium(III) oxide particles in the aqueous suspension show PAM 7.0_80 \% at pH 9. The mechanism of this process is solid surface charge neutralization by the adsorbed macromolecules.

Acknowledgments The study was supported by the Polish National Center of Science, Grant No. 2012/07/B/ST4/00534.

\section{References}

Anger G, Halstenberg J, Hochgeschwender K, Scherhag C, Korallus U, Knopf H, Schmidt P, Ohlinger M (2005) Chromium compounds. In: Ullmann's Encyclopedia of Industrial Chemistry. Wiley-VCH, Weinheim, chapter 4.1

Bielicka A, Bojanowska I, Wiśniewski A (2005) Two faces of chromium-pollutant and bioelement. Pol J Environ Stud 14:5-10

Entry JA, Sojka RE, Watwood M, Ross C (2002) Polyacrylamide preparations for protection of water quality threatened by agricultural runoff contaminants. Environ Pollut 120:191-200

Gościańska J, Nowak I, Nowicki P, Pietrzak R (2012) The influence of silver on the physicochemical and catalytic properties of activated carbons. Chem Eng J 189-19:422-430

Gupta VK, Ali I (2004) Removal of lead and chromium from wastewater using bagasse fly ash - a sugar industry waste. J Colloid Interface Sci 271:321-328

Gupta VK, Rastogi A (2009) Biosorption of hexavalent chromium by raw and acid-treated green alga Oedogonium hatei from aqueous solutions. J Hazard Mater 163:396-402

Gupta VK, Saleh TA (2013) Sorption of pollutants by porous carbon, carbon nanotubes and fullerene-an overview. Environ Sci Pollut Res 20:2828-2843

Gupta VK, Ali I, Saini VK (2007) Defluoridation of wastewaters using waste carbon slurry. Water Res 41:3307-3316

Gupta VK, Jain R, Saleh TA, Nayak A (2011a) Equilibrium and thermodynamic studies on the removal and recovery of safranine-T dye from industrial effluents. Sep Sci Technol 46:839-846

Gupta VK, Agarwal S, Saleh TA (2011b) Chromium removal combining the magnetic properties of iron oxide with adsorption properties of carbon nanotubes. Water Res 45:2207-2212

Gupta VK, Agarwal S, Saleh TA (2011c) Synthesis and characterization of alumina-coated carbon nanotubes and their application for lead removal. J Hazard Mat 185:17-23

Gupta VK, Ali I, Saleh TA, Nayak A, Agarwal S (2012a) Chemical treatment technologies for waste-water recycling-an overview. RSC Adv 2:6380-6388

Gupta VK, Pathania D, Agarwal S, Sharma S (2012b) Removal of Cr (VI) onto ficus carica biosorbent from water. Environ Sci Pollut Res 20:2632-2644

Gupta VK, Jain R, Mittal A, Saleh TA, Nayak A, Agarwal S, Sikarwar S (2012c) Photo-catalytic degradation of toxic dye amaranth on $\mathrm{TiO}_{2} / \mathrm{UV}$ in aqueous suspensions. Mater Sci Eng C 32:12-17

Gupta VK, Kumar R, Nayak A, Saleh TA, Barakat MA (2013) Adsorptive removal of dyes from aqueous solution onto carbon nanotubes: a review. Adv Colloid Interface Sci 193-194:24-34 
Haydar S, Aziz JA (2009) Coagulation-flocculation studies of tannery wastewater using combination of alum with cationic and anionic polymers. J Hazard Mater 168:1035-1040

Janusz W (1999) Electrical double layer at the metal oxide/electrolyte interface in interfacial forces and fields: theory and applications. In: Decker M (ed) Surfactant science series, vol 85, chapter 4. New York

Jin YZ, Zhang YF, Chen XP, Gao HS (2003) Application of organic polymeric flocculants in centrifugal dewatering of oil refinery sludge. J Environ Sci (China) 1:510-513

Kasprzyk-Hordern B (2004) Chemistry of alumina, reactions in aqueous solution and its application in water treatment. Adv Colloid Interface Sci 110:19-48

Kaźmierczak J, Nowicki P, Pietrzak R (2013) Sorption properties of activated carbons obtained from corn cobs by chemical and physical activation. Adsorption 19:273-281

Nasser MS, James AE (2006) The effect of polyacrylamide charge density and molecular weight on the flocculation and sedimentation behaviour of kaolinite dispersions. Sep Purif Technol 52:241-252

Nosal-Wiercińska A (2012) Electrochemical and thermodynamic study of the electroreduction of $\mathrm{Bi}(\mathrm{III})$ ions in the presence of cystine in solutions of different water activity. J Electroanal Chem 681:103-108

Nosal-Wiercińska A (2013) The role of active complexes in the multistep process of $\mathrm{Bi}(\mathrm{III})$ ion electroreduction in chlorate(VII) solutions with varied water activity in the presence of cysteine. Electrochim Acta 92:397-403

Nosal-Wiercińska A (2014) Intermolecular interactions in systems containing $\mathrm{Bi}(\mathrm{III})-\mathrm{ClO}_{4}{ }^{-}-\mathrm{H}_{2} \mathrm{O}$ - selected amino acids in the aspect of catalysis of $\mathrm{Bi}(\mathrm{III})$ electroreduction. Electroanalysis 26:1013-1023

Nowicki P, Kuszyńska I, Pietrzak J, Przepiórski R (2013) The effect of chemical activation method on properties of activated carbons obtained from pine cones. Cent Eur J Chem 11:78-83

Nowicki P, Kaźmierczak J, Pietrzak R (2015) Comparison of physicochemical and sorption properties of activated carbons prepared by physical and chemical activation of cherry stones. Powder Technol 269:312-319

Oliveira H (2012) Chromium as an environmental pollutant: insights on induced plant toxicity. J Bot, ID 375843

Ostolska I, Wiśniewska M (2014a) Comparison of the influence of polyaspartic acid and polylysine functional groups on the mechanism of polymeric film formation at the $\mathrm{Cr}_{2} \mathrm{O}_{3}$-aqueous solution interface. Appl Surf Sci 311:734-739

Ostolska I, Wiśniewska M (2014b) Application of the zeta potential measurements to explanation of colloidal $\mathrm{Cr}_{2} \mathrm{O}_{3}$ stability mechanism in the presence of the ionic polyamino acids. Colloid Polym Sci 292:2453-2464

Ostolska I, Wiśniewska M (2015) Investigation of the colloidal $\mathrm{Cr}_{2} \mathrm{O}_{3}$ removal possibilities from aqueous solution using the ionic polyamino acid block copolymers. J Hazard Mater 290:69-77

Pefferkorn E (1999) Polyacrylamide at solid/liquid interfaces. J Colloid Interface Sci 216:197-220

Saleh TA (2011) The influence of treatment temperature on the acidity of MWCNT oxidized by $\mathrm{HNO}_{3}$ or a mixture of $\mathrm{HNO}_{3} /$ $\mathrm{H}_{2} \mathrm{SO}_{4}$. Appl Surf Sci 257:7746-7751

Saleh TA (2015a) Isotherm, kinetic, and thermodynamic studies on $\mathrm{Hg}$ (II) adsorption from aqueous solution by silica-multiwall carbon nanotubes. Environ Sci Pollut Res. doi:10.1007/s11356015-4866-z
Saleh TA (2015b) Nanocomposite of carbon nanotubes/silica nanoparticles and their use for adsorption of $\mathrm{Pb}$ (II): from surface properties to sorption mechanism. Desalin Water Treat. doi:10. 1080/19443994.2015.1036784

Saleh TA, Gupta VK (2012a) Photo-catalyzed degradation of hazardous dye methyl orange by use of a composite catalyst consisting of multi-walled carbon nanotubes and titanium dioxide. J Colloid Interface Sci 371:101-106

Saleh TA, Gupta VK (2012b) Processing methods, characteristics and adsorption behavior of tire derived carbons: a review. Adv Colloid Interface Sci 211:93-101

Saleh TA, Gupta VK (2012c) Synthesis and characterization of alumina nano-particles polyamide membrane with enhanced flux rejection performance. Sep Sci Technol 89:245-251

Saleh TA, Gupta VK (2012d) Column with CNT/magnesium oxide composite for lead (II) removal from water. Environ Sci Pollut Res 19:1224-1228

Saleh TA, Agarwal S, Gupta VK (2011) Synthesis of MWCNT/MnO and their application for simultaneous oxidation of arsenite and sorption of arsenate. Appl Catal B 106:46-53

Sarker BC, Basak B, Islam MS (2013) Chromium effects of tannery waste water and appraisal of toxicity strength reduction and alternative treatment. Int J Agron Agric Res 3:23-35

Scoggins MW, Miller JW (1975) Spectrophotometric determination of water soluble organic amides. Anal Chem 47:152-154

Sojka RE, Entry JA (2000) Influence of polyacrylamide application to soil on movement of microorganisms in runoff water. Environ Pollut 108:405-412

Sojka RE, Bjorneberg DL, Entry JA, Lentz RD, Orts WJ (2007) Polyacrylamide in agriculture and environmental land management. Adv Agron 92:75-162

Szewczuk-Karpisz K, Wiśniewska M (2014) Adsorption properties of the albumin-chromium(III) oxide system-effect of solution $\mathrm{pH}$ and ionic strength. Soft Mater 12:268-276

Szewczuk-Karpisz K, Wiśniewska M, Pac M, Choma A, Komaniecka I (2014) Sinorhizobium meliloti 1021 exopolysaccharide as a flocculant improving chromium(III) oxide removal from aqueous solutions. Water Air Soil Pollut 225:2052

Taylor KC, Nasr-El-Din HA (1998) Water-soluble hydrophobically associating polymers for improved oil recovery: a literature review. J Pet Sci Eng 19:265-280

Tripathy T, De BR (2006) Flocculation: a new way to treat the waste water. J Phys Sci 19:93-127

Wiśniewska M, Szewczuk-Karpisz K (2013) Removal possibilities of colloidal chromium(III) oxide from water using polyacrylic acid. Environ Sci Pollut Res 20:3657-3669

Wiśniewska M, Chibowski S, Urban T (2013) Investigations of flocculation possibilities of the water alumina suspension in the presence of nonionic polymer. $J$ Ind Eng Chem 19:263-271

Wiśniewska M, Chibowski S, Urban T (2015a) Effect of the presence of cationic polyacrylamide on the surface properties of aqueous alumina suspension-stability mechanism. Appl Surf Sci 320:843-851

Wiśniewska M, Chibowski S, Urban T (2015b) Impact of polyacrylamide with different contents of carboxyl groups on the chromium(III) oxide adsorption properties in aqueous solution. J Hazard Mater 283:815-823

Xia L (2007) The role of cationic polyacrylamide in the reverse flotation of diasporic bauxite. Miner Eng 20:1191-1199 
Yuan ZY, Hu HR, Wen YB (2011) Synthesis and application of glyoxalted polyacrylamide paper strengthening agent. Adv Mater Res 236-238:1385-1390

Zhang XC, Miller WP (1996) Polyacrylamide effect on infiltration and erosion in furrows. Soil Sci Soc Am J 60:866-872
Zolfaghari R, Katbab AA, Nabavizadeh J, Tabasi RY, Nejad MH (2006) Preparation and characterization of nanocomposite hydrogels based on polyacrylamide for enhanced oil recovery applications. J Appl Polym Sci 100:2096-2103 